\title{
A MOROSIDADE PROCESSUAL E O DESENCONTRO COM OS PRINCÍPIOS CONSTITUCIONAIS QUE CAUSAM TRANSTORNOS AOS ADVOGADOS
}

\section{PROCEDURAL MOROSITY AND DISAGREEMENT WITH CONSTITUTIONAL PRINCIPLES THAT CAUSE PROBLEMS FOR LAWYERS}

\author{
Charleston Sperandio de Souza \\ Mestre e Professor de Administração e Economia e Orientador pela Alfa Unipac, \\ Aimorés/MG, Brasil \\ E-mail: charleston.sperandio@yahoo.com.br
}

\author{
Mirelly Neitzel Sperandio de Souza \\ Graduanda do $7^{\circ}$ período de Direito, pelo Centro Universitário do Espírito Santo - \\ UNESC - Colatina/ES, Brasil \\ E-mail: mirelly_neitzel@hotmaill.com
}

Recebido: 15/10/2020 - Aceito: 27/11/2020

\section{Resumo}

O objetivo deste estudo foi identificar as causas que emperram o andamento processual e que provocam transtornos aos advogados. Para analisar as causas da morosidade processual foram estudadas algumas obras científicas que tratam do assunto de alguns juristas brasileiros e foi ouvido as contribuições de seis advogados atuantes no Poder Judiciário. A morosidade processual é um problema que existe há tempos não só no arcabouço do Sistema Jurídico brasileiro, como em quase todos os ordenamentos correlacionados. Como são recorrentes as ocorrências da morosidade processual, os operadores do direito estão constantemente procurando as causas dessa problemática, para poderem contribuir de forma a minimizar ou exterminar a morosidade processual. A metodologia utilizada foi qualitativa, pois visou proporcionar maior familiaridade com o objetivo da pesquisa, com vistas a torná-lo mais explícito por meio das interpretações das respostas utilizando a subjetividade. Foi realizado uma pesquisa de campo, com aplicação de um questionário aberto, com opiniões de seis advogados sobre o tema. Independente dos achados nesse estudo, o mesmo deve ter um maior aprofundamento pelo Poder Judiciário para encontrar outras origens da morosidade e que possam gerar novas prevenções pelo Sistema Jurídico. Os resultados apontaram que 0 aumento de números de processos gera congestionamento dos mesmos, a quantidade de recursos existentes impetrados pelos advogados, a ausência de recursos materiais e o excesso de trabalho foram as principais causas encontradas. Concluiu-se que os princípios constitucionais devem ser totalmente respeitados, pois é direito e garantia fundamental a razoável duração do processo.

Palavras chaves: Justiça; normas; doutrina; constituição federal. 


\section{Abstract}

The aim of this study was to identify the causes that are the case with the procedural progress and that cause disorders to lawyers. To analyze the causes of procedural delay, some scientific works dealing with the subject of some Brazilian jurists were studied and the contributions of six lawyers who work in the judiciary were heard. Procedural slowness is a problem that has existed for a long time not only in the framework of the Brazilian Legal System, but also in almost all correlated systems. As the occurrences of procedural delay are recurrent, the operators of law are constantly seeking the causes of that problem in order to be able to contribute in order to minimise or exterminate the procedural delay. The methodology used was qualitative, because it aimed to provide greater familiarity with the objective of the research, with a view to making it more explicit through the interpretations of the answers using subjectivity. A field research was carried out, with the application of an open questionnaire, with opinions of six lawyers on the subject. Regardless of the findings in this study, it should have a deeper deepening by the Judiciary to find other origins of slowness and that can generate new preventions by the Legal System. The results showed that the increase in the number of cases generates congestion of the same, the amount of existing resources filed by lawyers, the absence of material resources and overwork were the main causes found. It was concluded that the constitutional principles must be fully respected, as the reasonable duration of the proceedings is a fundamental right and guarantee.

Keywords: Justice; norms; doctrine; federal constitution.

\section{Introdução}

$\mathrm{Na}$ atualidade, o conjunto de forças que despendem os serventuários do Poder Judiciário, o Ministério Público e o Juiz de Direito para dar velocidade aos processos, e as dificuldades enfrentadas pelos advogados no campo da morosidade processual no ordenamento jurídico brasileiro, são atributos cada vez mais indissociáveis, que se abarcam e transpõem a máquina judiciária.

Neste estudo, investigar-se-á a concepção da Justiça em confronto com o ponto central do tema "morosidade processual", como solucionar os conflitos com os princípios constitucionais que causam transtornos aos advogados e as atitudes dos desempenhos dos Juízes de Direito no campo do andamento processual.

Este tema se revela nos dias atuais em detrimento da complexidade das demandas da sociedade que são dirigidas ao Poder Judiciário, em que se depara com um cenário de estagnação de tal Poder, como instrumento legítimo de dar celeridade e soluções aos processos, como forma normativa e ideal ao desempenho das partes dos Juízes de Direito e dos demais colaboradores processuais, que estabelece a 
forma esperada do processo sob a expectativa da Justiça e da equidade nas saídas dos diferentes conflitos verificados no bojo da sociedade.

A apreciação do tema morosidade processual tem como fonte fundamental nos processos instaurados para o apuramento da culpabilidade ou não dos cidadãos em diversos casos (ADORNO; PASINATO, 2007).

De acordo com esse entendimento, as pesquisas apontam que há uma discrepância ampla entre a Norma Jurídica brasileira e a sua aplicação; e segundo Vargas (2004), em uma análise mais profunda nos Manuais de Direito, o período prescrito pelos processos tem por desígnio em consentir a aplicação de um direito que resguarde as garantias constitucionais e dê celeridade.

Isto requer uma transformação de mentalidade dos Juízes, que precisarão conseguir uma esperteza jurídica e não exclusivamente em casos individuais e simplesmente submetidos à sua aplicação particular no processo (CHIUVITE JÚNIOR, 2010).

O presente estudo se justifica por meio da observação que agrega relevância à escolha da área de estudo, quando se analisa a Emenda Constitucional (EC) ㄲo 45 de 30 de dezembro de 2004 em seu inciso LXXVIII, que alterou os dispositivos do artigo 5 da Constituição Federal (CF) de 1988, e estabeleceu a previsão do tempo de duração razoável do processo como garantia plena ao cidadão, que diz: "a todos, no âmbito judicial e administrativo, são assegurados a razoável duração do processo e os meios que garantam a celeridade de sua tramitação".

Por conta da observação sistemática da EC nำ45, o Legislador Constituinte sagrou não o acabamento presumível do processo na medida do possível ou uma tardança tolerável, entretanto procurou dar ação e celeridade na tramitação dos casos, ou seja, o princípio da razoabilidade em que a permanência do processo necessita ser combinado com o acontecimento da rapidez, mesmo porque, como constitui o artigo $1^{\circ}$ do Estatuto Processual de 2015, que o processo [...] será ordenado, disciplinado $\mathrm{e}$ interpretado conforme os valores $\mathrm{e}$ as normas fundamentais estabelecidas na Constituição da República Federativa do Brasil (OLIVEIRA, 2016).

Dessa forma, a justificativa pelo interesse jurisdicional sobre a morosidade processual também impulsiona a comunidade acadêmica dos graduandos em direito em dedicar esforços para produzir estudos dentro desse campo temático. Assim, a contribuição do estudo para a literatura, está associada à utilização de pesquisas 
amplamente estudadas na comunidade acadêmica nacional, contribuindo para a sua discussão no ambiente da graduação de direito.

Portanto, este artigo assume o objetivo de identificar as possíveis causas da morosidade processual que causam transtornos aos advogados no ordenamento jurídico brasileiro.

Assim, entende-se que nos capítulos a serem apresentados constarão as propostas do assunto desta pesquisa e serão possíveis apontar as evidências a serem delineadas, que corroboram com o espaço dos operadores do direito e as dificuldades de lidar com a morosidade processual de maneira determinista, no alcance em que abarcam infinitas implicações nos meios Jurídicos e Sociais.

Para superar essas limitações de entender o desenvolvimento das teorias e das práticas que tentam controlar, minimizar ou reduzir os efeitos da morosidade processual, pretende-se investigar vários estudos, dentre os quais citam-se Reale (1986); (1991) e (2004); Oliveira (2016), Mendes (2012); Costa (2018); CONSELHO NACIONAL DE JUSTIÇA (2014) dentre outros, bem como um estudo de campo tão importante como os quais que aqui foram citados.

Desse modo, há de se convir que a temática é ampla e que é necessário que seja estudada continuamente para corroborar o que este modesto estudo buscou revelar.

\subsection{A Morosidade Processual da Justiça Brasileira}

A morosidade processual da justiça brasileira não é fato novo, tanto que a Emenda à Constituição (EC) nº 45/2004 elevou à cláusula pétrea1 alterando o art. 5ํ, inciso LXXVIII, da CF de 1988, que diz respeito sobre "o direito de razoável duração do processo no âmbito judicial e administrativo" e a mesma EC 45/2004, igualmente alterou o artigo 93 inciso XV da CF de 1988, que presume a "imediata distribuição dos processos em todos os graus de jurisdição", que se encontra no bojo da mesma emenda constitucional.

\footnotetext{
${ }^{1}$ Cláusula Pétrea é um artigo da Constituição Federal que não pode ser modificado. Uma cláusula é um artigo de uma lei, é parte do texto jurídico que define direito ou obrigações. Disponível em <https://www.significados.com.br/clausula-petrea/> Acesso em 16 Out. 2019.
} 
A morosidade processual é um problema que existe há tempos não só no arcabouço jurídico brasileiro, bem como em quase todos os ordenamentos jurídicos equiparados. Por essa problemática, além de antigo, sabe-se que é universal e podese dar como exemplo a Itália - considerada a pátria dos mais extraordinários processualistas da história, a qual é o país europeu que proporciona os maiores indicadores de lentidão na prestação judicial (MENDES, 2012).

Vale ressaltar como exemplo no Brasil, em que a Comissão de Constituição, Justiça e Cidadania (CCJ) do Senado Federal brasileiro sabatinou o advogado Henrique Ávila, para a vaga reservada ao Senado no CNJ (Conselho Nacional de Justiça) e Ávila em sua fala, assinalou para uma incongruência no Poder Judiciário brasileiro, sendo "um dos mais lentos do mundo, a despeito de possuir na média os Juízes entre os mais produtivos, com cerca de 1.616 processos julgados por ano". $\mathrm{Na}$ Itália, comparou Ávila, cada juiz julga 959 processos por ano, enquanto na Espanha são 689 processos por ano e em Portugal 397 (AGÊNCIA SENADO, 2016).

Para corroborar com a fala de Ávila e demonstrar o cenário da morosidade processual brasileira, na tabela 1 demonstra um estudo encomendado no ano de 2005 pelo Supremo Tribunal Federal - STF, ao Centro de Pesquisas de Opinião Pública da Universidade de Brasília (UnB), segundo Costa (2018).

O estudo objetivou-se a questionar o seguinte: Se Vale a pena procurar a justiça? e Porque não vale a pena procurar a justiça?

Tabela 1. Estudo estatístico realizado pelo STF sobre a realidade do Poder Judiciário do Brasil. Vale a pena procurar a justiça?

\begin{tabular}{l|c|c|c}
$\begin{array}{c}\text { VALE A PENA } \\
\text { PROCURAR A } \\
\text { JUSTIÇA? }\end{array}$ & FREQUÊNCIA & PERCENTUAL (\%) & $\begin{array}{c}\text { PERCENTUAL VÁLIDO } \\
(\%)\end{array}$ \\
\hline Sim & 1.589 & 80,0 & 82,2 \\
\hline Não & 345 & 17,4 & 17,8 \\
\hline Total com resposta & 1.935 & 97,4 & 100,0 \\
\hline Não Sabe & 52 & 2,6 & $\cdots--$ \\
\hline Total & 1.986 & 100,0 & $-\cdots$ \\
\hline
\end{tabular}

Fonte: Data UnB, (2005). (Adaptado pela autora).

O estudo identificou que $17,8 \%$ dos entrevistados, acham que "não vale a pena procurar a Justiça".

Então, esses entrevistados que deram as respostas como "não vale a pena procurar a justiça", foram questionados sobre as possíveis motivações do "por que não vale a pena procurar a justiça", e demonstra-se o resultado na tabela 2 a seguir: 
Tabela 2, Estudo estatístico realizado pelo STF sobre a realidade do Poder Judiciário do Brasil. Porque não vale a pena procurar a justiça?

\begin{tabular}{l|c|c|c}
\hline $\begin{array}{c}\text { POR QUE NÃO } \\
\text { VALE A PENA } \\
\begin{array}{l}\text { PROCURAR A } \\
\text { JUSTIÇA? }\end{array}\end{array}$ & FREQUÊNCIA & PERCENTUAL (\%) & $\begin{array}{c}\text { PERCENTUAL VÁLIDO } \\
(\%)\end{array}$ \\
\hline $\begin{array}{l}\text { A Justiça é } \\
\text { demorada }\end{array}$ & 137 & 6,9 & 42,6 \\
\hline A Justiça é cara & 33 & 1,6 & 10,1 \\
\hline $\begin{array}{l}\text { A Justiça não } \\
\text { funciona }\end{array}$ & 61 & 3,1 & 19,0 \\
\hline Não é confiável & 78 & 3,9 & 24,2 \\
\hline Não justificou & 13 & 0,7 & 4,1 \\
\hline Total com resposta & 323 & 16,3 & $-\cdots, 0$ \\
\hline Não sabe & 79 & 4,0 & $\cdots$ \\
\hline Não se aplica & 1.585 & 79,8 & --- \\
\hline Total & 1.986 & 100,0 & \\
\hline
\end{tabular}

Fonte: Data UnB, (2005). (Adaptado pela autora).

Os entrevistados demonstraram "a morosidade da Justiça" como principal fator que "não vale a pena procurar a justiça", alcançando $42,6 \%$ do resultado (COSTA, 2018).

Pode-se perceber que a morosidade do Poder Judiciário causa uma extenuação no chamado "acesso à justiça". Essa declaração não pode ser confundida com o acesso ao Poder Judiciário, ou seja, a possibilidade do ingresso no Poder Jurisdicional do Estado.

Como são recorrentes os fatos da morosidade processual, os operadores do direito sempre procuraram as fontes ou causas dessa problemática, tentando descobrir as maneiras de minimizar os efeitos ou exterminá-las (MENDES, 2012).

Dessa forma, o CNJ descreve que a morosidade processual no Poder Judiciário é o protesto de aproximadamente a metade dos cidadãos brasileiros que buscam a Ouvidoria do CNJ. Segundo o relatório do órgão, que atua como canal de comunicação entre o Conselho e a população, dos 5.070 atendimentos realizados pela Ouvidoria em 2014, 2.306 foram relacionados à demora no julgamento de ações judiciais (CNJ, 2014).

Por outro viés, não se pode excluir do presente estudo a taxa de congestionamento de processos no Poder Judiciário. Em toda a série histórica, a taxa se conservou em patamares elevados, sempre acima de $70 \%$. As variações anuais são clarividentes e, em 2017, houve diminuição de um ponto percentual. Ao longo de oito anos, a taxa de congestionamento variou em apenas 1,5 pontos percentual. $\mathrm{A}$ 
taxa de congestionamento bruta do Poder Judiciário caiu de 73\% em 2016, para 72\% em 2017, de acordo com o CNJ (CNJ, 2018).

Outra fonte de pesquisa foi realizada em 2010 pela FUNDACE² (Fundação para Pesquisa e Desenvolvimento da Administração, Contabilidade e Economia, ligada aos professores da FEA-RP/USP), o índice variou de 0 a 100 pontos e apontou a morosidade, desigualdade de tratamento e alto custo como os principais pontos fracos no Poder Judiciário. Nessa pesquisa foram ouvidos 644 advogados de todo 0 território brasileiro.

A pesquisa apontou ainda que os advogados brasileiros deram nota 31,7 para a confiança que possuem na Justiça brasileira. $O$ indicador é composto por sete índices calculados de acordo com as respostas dos advogados para os questionamentos sobre: igualdade de tratamento, eficiência, honestidade, rapidez, custos, acesso e expectativa quanto ao futuro da Justiça brasileira.

Porém, ao se tratar do quesito "rapidez" para tratar os litígios, foi o índice que obteve a pior pontuação, foram apenas 13,9 pontos de 100 possíveis, o que reforça a percepção de morosidade ou lentidão no poder judiciário. Para $98 \%$ dos entrevistados, a solução de litígios é lenta ou muito lenta e apenas $2 \%$ a consideram rápida.

Mendes (2012) em seu trabalho, relata que em qualquer doutrina, o parecer, o tratado, e o ordenamento é colocado como o vilão da conjuntura, ficando exposto à crítica social por meio da mídia como o único colaborador à morosidade. Esse autor atribui algumas causas às possíveis morosidades processuais, senão veja a primeira:

Quanto aos prazos, pode-se afirmar que estes não são a causa da ineficiência da prestação jurisdicional. Se todos os prazos propostos fossem cumpridos estritamente, o processo terminaria em um curto e ponderado espaço de tempo (MENDES, 2012, p.4).

O mesmo autor faz análise crítica acerca dos prazos, afirmando que os prazos estão recomendados adequadamente, nem tão alongados, mas que permitam um tempo ideal para uma defesa. $O$ problema é que os prazos não são cumpridos devidamente. Alguns sequer oferecem sanções aos seus descumprimentos.

Ainda na concepção de Mendes (2012), pode oferecer como exemplo, citar o prazo conferido aos juízes que determina o tempo para despachos e sentenças, os quais não propõem qualquer tipo de penalidade quando não respeitados.

\footnotetext{
${ }^{2}$ Disponível em <https://blog.fundace.org.br/2018/04/25/advogados-dao-nota-3-para-justica-brasileiraaponta-pesquisa-da-fundaceusp/>. Acesso em 16 out. 2019.
} 
Mendes (2012, p.4) cita uma segunda possível causa:

Quanto à quantidade de recursos existentes, pode-se expressar que são a consolidação de uma das atribuições fundamentais do Estado de Direito, o princípio do Duplo Grau de Jurisdição. Este é um princípio constitucional atuante e extremamente importante. Com a quantidade de processos diretamente ligados à estrutura judiciária, fica clara a afirmativa de que os juízes de primeiro grau não possuem a capacidade de julgar com tanta pessoalidade e aprofundamento todos os processos.

Mendes (2012) afirma que como o aparelho judiciário que por inteiro é lento, não criaria resultados positivos de eliminar garantias de segurança dos litigantes em benefícios de uma celeridade processual disfarçada. Ter-se-ia assim um processo que prosseguiria lento, visto que a abundância de recursos não são os essenciais fatores da morosidade processual.

Dessa forma, Spalding (2005) em um respeitável estudo, analisou o processo comum ordinário consoante a uma instauração à sua sentença em primeira instância, e chegou à conclusão, que a partir da contagem dos prazos legais instituídos, que o lapso do tempo total nesse processo, seria aproximadamente de 131 (cento e trinta e um) dias. Logo, provável seria que a permanência do processo comum ordinário girasse em volta desse período, do estabelecimento ao provimento final na primeira instância.

Ao trazer a identificação de algumas causas da morosidade na atividade jurisdicional, Tucci (1997) colabora com as razões dos estudos de Spalding (2005) e acrescenta mais dois fatores institucionais que motivam a morosidade processual. $O$ primeiro relacionado aos fatores de ordem da técnica processual e o segundo, aos fatores provenientes do carecimento de material.

Quanto ao primeiro fator, Tucci (1997) considera que o mesmo se arrola com a organização do Poder Judiciário, corroborado com a técnica processual e ao preparo dos Juízes e servidores, e o segundo se relaciona em relação aos recursos materiais, recursos financeiros, mão de obra e recursos tecnológicos à disposição da gestão administrativa.

Ao se repensar na técnica processual (primeiro fator) esse pode conduzir a diminuição do lapso temporal do processo, mesmo com a configuração não tão expressiva. Enseja manifestar que os de ordens de gestão administrativa, esses se apresentam como os fatores que mais implicam a morosidade processual no exercício da Justiça (ROCHA, 2011). 


\subsection{A Lei, A Justiça e alguns Conceitos de Princípios Constitucionais}

O universo jurídico é composto pelo dualismo entre a Lei e a Justiça. A Lei corresponde sistematicamente à cobrança necessária de um convívio ordenado, pois nenhuma sociedade poderia sobreviver sem uma ordem, e a Justiça é o resultado da aplicação prática que norteia a Legislação (FUX, 2001).

Dessa forma, Ribeiro (2000, p. 296) destaca que existe uma crise na Legislação e uma crise na esfera Judicial. Essas crises derivam da distorção entre a Lei e os anseios sociais e da "ineficiência da realização da Justiça", assim a Lei e a Justiça "compõem as duas faces deste universo sobre o qual gravitam todos os fenômenos jurídicos".

Barbosa (1920, p.40,) apud Costa (2018, p.10) relata que "justiça atrasada não é justiça, senão injustiça qualificada [...] porque a dilação ilegal nas mãos do julgador contraria o direito [...] das partes, [...] lesa o patrimônio, a honra e a liberdade" e Reale (2004) corrobora afirmando que após reiterados estudos e debates acerca da crise da Justiça, foram determinadas diversas razões da lentidão ou morosidade processual para obter as sentenças decisivas e consequentemente a sua imediata execução, avaliando que justiça tardia é nenhuma justiça.

Para alinhar a investigação ao tema proposto, de acordo com os entendimentos de Fux (2001) é legítimo que o Poder Judiciário sofre no Brasil, e a crise vivenciada tem dupla ratio essend ${ }^{3}$, ou seja, a não sintonia entre a legislação e os anseios da sociedade e a não eficiência da aplicação da Lei.

Sobre as fundamentais funções dos princípios constitucionais e a sua relevância ao sistema normativo, Reale (1986, p. 60) enfatiza que os "princípios são verdades [...] fundamentais, que servem de [...] garantia [...] a um conjunto de juízos, ordenados em um sistema de conceitos relativos à [...] porção da realidade"

Como regra, os princípios constitucionais desempenham com eficácia a criação e a interpretação de todas as normas jurídicas, como também oferecem suporte às decisões dos tribunais, e impõem deveres e obrigações aos cidadãos em todas as esferas, além de promover direitos subjetivos (DOVERA, 2012), e a autora

\footnotetext{
3 Teoria da absoluta dependência, que significa que há uma dependência entre o delito tipicidade. Disponível em < https://www.dicionarioinformal.com.br/ratio+essendi/? Acesso em 16 out. 2019
} 
enfatiza ainda mais, os princípios constitucionais compõem o embasamento primordial de um sistema jurídico, cujo foco principal é o cumprimento da justiça e o contentamento dos direitos fundamentais.

Já Bonavides (2012) relata que os princípios constitucionais majoram a um patamar de superioridade e supremacia, garantindo a permanecerem no ápice da normatividade que baseia o poder.

Como última posição doutrinária como exemplo, pode-se trazer novamente o pensamento clássico de Reale (1991, p. 299), em sua outra obra, em que o autor trata os princípios como pressupostos de conhecimento

Os princípios são 'verdades fundantes' de um sistema de conhecimento, como tais admitidas, por serem evidentes ou por terem sido comprovadas, mas também por motivos de ordem prática de caráter operacional, isto é, como pressupostos exigidos pelas necessidades da pesquisa e da "práxis".

Então, compreende-se que os princípios constitucionais compõem a estrutura, o sustentáculo e o marco inicial dos ordenamentos jurídicos, sendo-lhe negado o papel de complemento do Direito de acordo com Bonavides (2012), e ainda seguindo suas mais básicas características, demonstrou conceitos finais, ou seja, apresentou o adequado objetivo da norma sem comprovar os caminhos que se devem percorrer.

\subsection{A Tecnologia como tentativa de dar celeridade aos Processos}

$\mathrm{Na}$ esfera do direito processual brasileiro, as soluções refletidas pelos estudiosos da área, partiram do princípio de que era indispensável introduzir inovações tecnológicas no Sistema Processual para diminuir a lentidão, a morosidade e o inadequado processo.

Dentro dos princípios, surgiram propostas que influenciaram no aparecimento da percepção instrumentalista, que, em tese, protegia o esforço das atividades dos Juízes, consentindo a esses um desempenho voltado às finalidades metajurídicas (sociais, políticos e econômicos) do processo.

Ao contrário da morosidade processual, não se pode omitir que houve a implantação da Lei $11.419 / 2006^{4}$ que diz respeito sobre a informatização do processo judicial (processo eletrônico/virtual) pelos Tribunais, que teve a intenção em dar

\footnotetext{
${ }^{4}$ Dispõe sobre a informatização do processo judicial; altera a Lei no 5.869 , de 11 de janeiro de 1973 Código de Processo Civil; e dá outras providências. Disponível em <

http://www.planalto.gov.br/ccivil_03/_Ato2004-2006/2006/Lei/L11419.htm> Acesso em 01 nov 2019.
} 
celeridade aos processos, e se tornou impossível em não absorver o princípio da disciplina do CNJ e sua plena absorção pelo Superior Tribunal de Justiça (STJ) e Supremo Tribunal Federal (STF), como possível solução de celeridade processual (ABRÃO, 2013).

As ações impetradas na Justiça por meio do Processo Judicial Eletrônico (PJe) tem tramitação com mais celeridade e de menor duração em comparação aos processos físicos. Essa é uma das comprovações da pesquisa encomendada pelo CNJ sobre a implantação dos processos eletrônicos nos tribunais (CNJ, 2018).

O CNJ (2018) informa ainda que de acordo com a pesquisa, enquanto os processos físicos apontam uma média de 144 (cento e quarenta e quatro) dias no tempo em cartórios, os processos judiciais eletrônicos apresentam uma média de 97 (noventa e sete) dias, o que sugere uma redução de $48 \%$ do período no trâmite pelo PJe.

A partir dessa análise, o PJe apontou ganhos no período que leva, para que os juízes pronunciem decisões em processos conclusos. No entanto, entende-se que o PJe sugere um efeito positivo para além dos efeitos óbvios esperados e contrasta com o pessimismo que os órgãos do Poder Judiciário vêm enfrentando dia a dia (FOLLE; SCHELEDER, 2014).

Por outro viés, ainda não são todas as comarcas do Brasil que possuem este sistema virtual em funcionalidade, também não há uma uniformização do mesmo. 0 que se analisa é que cada órgão do Poder Judiciário possui um sistema para o acesso ao processo eletrônico, o que acaba por dificultar a vida dos operadores do direito, trazendo à baila as desvantagens do PJe (FOLLE; SCHELEDER, 2014).

\section{Metodologia}

A metodologia utilizada para esse tipo de investigação é qualitativa, pois visou proporcionar maior familiaridade com o objetivo da pesquisa, com vistas a torná-lo mais explícito por meio da análise da subjetividade.

Demo (2000) destaca que os movimentos em torno da pesquisa qualitativa procuram confrontar-se com os exageros da formalização, mostrando-nos que a qualidade é menos questão de expansão do que de intensidade. Deixá-la de fora, seria deturpação dos fatos. 
Para Denzin e Lincoln (2006), a pesquisa qualitativa desvenda uma extensa, considerável e, por vezes, a história nas disciplinas humanas. No campo da sociologia, o estudo realizado pela "escola de Chicago" nas décadas de 1920 e 1930 motivou a relevância da investigação qualitativa para o estudo da vida dos humanos.

Após a preferência do tema, a autora iniciou um amplo levantamento das bases de dados como SciELO Brasil, Ebsco Host, Portal de Periódicos CAPES/MEC, Revista dos Tribunais e outras para encontrar relatórios de pesquisas em artigos científicos, dissertações de mestrados e outros, com o objetivo de elaborar a contextualização da pesquisa e seu embasamento teórico.

Nesse sentido, para fornecer subsídios práticos à pesquisadora, considerouse necessário em realizar uma enquete com 5 perguntas, por meio da aplicação de questionário aberto, para obter opiniões subjetivas de seis advogados atuantes no município de Baixo Guandu/ES, cidade em que reside a autora do estudo.

Para esse fim, foram utilizados os recursos da internet. De acordo com Malhotra (2006) as pesquisas desempenhadas por meio da Internet têm o princípio de notoriedade entre os pesquisadores; assim a Internet é utilizada como meio de comunicação e oferece distintas oportunidades para a concretização de pesquisas qualitativas.

Dos 10 (dez) questionários enviados aos advogados (as), somente 6 (seis) foram devolvidos no período estabelecido pela autora. Dessa forma, 4 (quatro) advogados (as) não responderam. Os (as) advogados (as) foram codificados pela autora como Adv1, Adv2, Adv3, Adv4, Adv5 e Adv6.

Consoante às respostas dos (das) advogados (as), as mesmas foram remetidas à interpretação conclusiva da pesquisa. Nesse sentido, entendeu-se que todo projeto de pesquisa deve conter as premissas ou os pressupostos teóricos e práticos sobre os quais a pesquisadora se fundamentou à sua interpretação.

Dessa forma, o método aplicado serviu de embasamento à interpretação subjetiva dos fatos analisados teóricos e práticos.

\section{Resultados e Discussão}

As perguntas que foram enviadas aos (as) advogados (as) entrevistados (as) de forma aberta, exigiram respostas em forma de frases descritivas dos (as) 


\section{Revista Multidisciplinar do Nordeste Mineiro, 2020/02 \\ ISSN 2178-6925}

respondentes, que se passa a expor por fragmentos por meio da interpretação da autora:

Questionamento 1) Perguntou-se qual é a sua percepção acerca da morosidade/lentidão dos andamentos processuais no Poder Judiciário da Comarca de Baixo Guandu/ES? (Na sua percepção, se existe ou não a morosidade processual). Por meio dessa pergunta, buscou-se levar aos respondentes a apresentarem suas percepções acerca da morosidade processual e todos os (as) advogados (as) foram unânimes em responder: Guandu".

"tem morosidade e lentidão nos processos que tramitam na Comarca de Baixo

A autora faz uma ressalva em que o Adv1 fez uma inferência acerca do questionamento 1 , que a maior crítica acerca dos processos morosos que tem como objetos as partilhas, inventários são competências da $2^{\underline{a}}$ vara criminal, ou seja, nessa vara encontra-se o maior gargalo dos processos lentos ou morosos.

Questionamento 2) Questionou-se quais são as prováveis causas que geram a morosidade/lentidão dos andamentos processuais no Poder Judiciário da Comarca de Baixo Guandu/ES?

As respostas tiveram várias interpretações:

"Falta de profissionais, principalmente assessores efetivos e Magistrados e elevado números de processos"; (Adv1; Adv2 e Adv4);

"No poder Judiciário de Baixo Guandu a justiça ainda é lenta devido a vários problemas, no caso, falta de funcionários efetivos, equipamentos e outros como a burocracia e a espera longa e onerosa de despachos e sentenças" (Adv3);

"A precarização do serviço do poder judiciário, uma vez que ocorreu a diminuição de funcionários efetivos e de estagiários" (Adv5);

"As prováveis causas, estas estão interelacionadas (sic!) entre todos os atos dos processos, desde uma causa simples até a mais complexa, que talvez justificaria (sic!) um lapso temporal maior, como também excessos de prazos e recursos nas demais instâncias" (Adv6).

Questionamento 3) Foi perguntado quais são as possíveis consequências ou transtornos que são gerados aos advogados (as) acerca da morosidade/lentidão processual na Comarca de Baixo Guandu?

Observa-se que todas as opiniões foram distintas:

"Desentendimentos dos advogados com Juízes, descréditos dos profissionais com os clientes, desânimo e fadiga profissional, problemas financeiros, etc." (Adv1); 
"Advogados ficam com a culpa pela demora" (Adv2);

"Transtornos tão grande e grave que atinge tanto advogados como a sociedade, demora nas conclusões dos feitos, processos como uma simples "disputa" leva em média 12 meses ou mais. Processos quando se trata de litígios, que envolve questões patrimoniais duram anos para serem resolvidos" (Adv3);

"Como na maioria dos processos ou quase a totalidade depende do resultado processual para haver ganho financeiro, e inexiste uma regularidade nos ganhos, alguns meses se faturam bem e outros poucos, além de gerar muitas cobranças por parte dos clientes insatisfeitos pela demora dos processos" (Adv4);

"Insatisfação da clientela, descrédito das pessoas com relação à atividade de advogado, muitas vezes responsabilizando o profissional pelo atraso, stress decorrentes das cobranças, diminuição dos rendimentos profissionais, etc" (Adv5);

"A lentidão processual desestrutura todos os serviços, ocasionando uma imensa insatisfação tanto para os operadores do direito quanto para as partes. Muito tempo perdido ocasionando prejuízos imensuráveis às partes, aos advogados e ao Erário" (Adv6).

Questionamento 4) Foi questionado: quais seriam as suas sugestões ou propostas para que haja celeridade no andamento processual na Comarca de Baixo Guandu? As respostas foram interpretadas como se demonstra:

"Aumento do quadro de profissionais, principalmente assessores de gabinete; e Magistrado por parte do Estado por meio de concurso público" (Adv1 e Adv2, Adv3, Adv4);

"Realização de mutirões para diminuir o acervo antigo, novos concursos para complementação do quadro de funcionários, estudo da viabilidade de contratação de terceirizados para algumas funções" (Adv5);

"Sugiro que todas as fases do processo sejam informatizadas como já acontece na justiça federal, mas também precisa de ter (sic!) profissionais suficientes comprometidos com o serviço e revisão de todo o fluxo e andamento desses processos em todas as suas fases ainda no juízo "a quo" (sic!). "Que o TJES deveria criar mais varas e reestruturar as varas existentes redistribuir os processos existentes, contratar mais servidores inclusive mais juízes e criar metas semanais a serem cumpridas" (Adv6).

Questionamento 5) Por fim, o último questionamento foi para perceber: qual é a sua atitude ou ação junto ao Poder Judiciário como um todo, ou à OAB quanto à morosidade/lentidão processual na Comarca de Baixo Guandu? (esta pergunta se reportou se o (a) advogado (a) recorre ao Juiz, ao Ministério Público, aos serventuários 


\section{Revista Multidisciplinar do Nordeste Mineiro, 2020/02 \\ ISSN 2178-6925}

dos cartórios, à $\mathrm{OAB}$, ou outros, sobre a morosidade/lentidão dos andamentos processuais).

Todos os respondentes chegaram às percepções diferenciadas:

"A atitude mais diplomática possível para evitar desgastes recorrendo a todos os envolvidos. Nunca levei ao "extremo" de comunicar à OAB ou outro mecanismo de controle fora do fórum" (Adv1);

"Infelizmente temos que pedir," por favor," para que os processos sejam analisados e despachado/sentenciados" (Adv2);

"Instalação de mais varas; o poder judiciário junto com a OAB invista na modernização da comarca, trazendo através de uma prestação jurisdicional célere adequada e de qualidade devendo existir números de juízes e servidores suficientes para dar conta da demanda processual, além disso há a necessidade de investimentos pesados em recursos tecnológicos e em materiais" (Adv3).

"Depende onde se localiza o processo. Se estiver na secretaria, se recorre ao serventuário da secretaria, se o processo estiver no gabinete concluso, se recorre ao assessor (a) do juiz (a) ou ao próprio juiz, em regra os processos que são abertos vistas ao MP, retornam rápidos" (Adv4).

"Todos os órgãos mencionados já foram acionados por esse profissional e na maioria das vezes de forma expressa, entretanto obtenção de resultados relevantes" (sic!) (Adv5).

"Atualmente sabemos que está ruim, mas também pode piorar mais ainda (sic!), principalmente se não tratar todos com urbanidade. As vezes se ficar cobrando muito, questionando muito se estressando, enfrentando as questões (de falta de celeridade) ainda se consegue alguma coisa, mas o sentimento é que todos os advogados estão hoje nesta comarca vivendo ou tentando sobreviver de favor de um ou outro servidor e também de juízes, vivemos pedindo favor e muitas das vezes as coisas não acontecem, já virou rotina, o que deveria ser regra, virou exceção, e ainda ferindo o princípio da impessoalidade no processo" (Adv6).

Nesse estudo, foram analisadas por meio da subjetividade as possíveis causas práticas que geram transtornos aos advogados de Baixo Guandu/ES.

Percebeu-se que as causas são diversas e recorrentes e que o aumento de números de processos no Poder Judiciário, faz o que se denomina congestionamento de processos, pois em toda a série histórica, a taxa se conservou em patamares elevados; a quantidade insuficiente de magistrados e servidores são fatores preponderantes para aumentar ainda mais a morosidade processual, afetando diretamente aos advogados e seus clientes, que pode ser corroborado pelos estudos de Mendes (2012) 
Também foi citado que a quantidade de recursos existentes impetrados pelos advogados e a carência de recursos materiais, deixa claro a afirmativa de que os Juízes de primeiro grau não possuem a capacidade de julgar com tanta pessoalidade e aprofundamento todos os processos com rapidez.

Ainda de acordo com a vivência na praticidade dos advogados respondentes trouxeram revelações sugestivas como aumentar o quadro de profissionais, principalmente assessores de gabinete e magistrados por parte do estado por meio de concurso público, realizar mutirões para diminuir o acervo antigo de processos, realizar novos concursos para complementação do quadro de funcionários, informatização processual e outros, podem ajudar a minimizar a morosidade processual, o que vai ao encontro dos estudos de Tucci (1997).

Já na análise teórica dos dados revelados pela Universidade de Brasília (UnB), que fez estudo solicitado pelo STF sobre a realidade do Poder Judiciário do Brasil, "se vale a pena procurar a justiça" e "por que não vale a pena procurar a justiça", o estudo identificou que $17,8 \%$ dos entrevistados, acham que "não vale a pena procurar a Justiça" e esses entrevistados identificados em 17,8\%, foram remetidos a outro questionamento do "por que não vale a pena procurar a justiça", e responderam que a "morosidade da Justiça" é o principal fator que não vale a pena procurar a justiça, alcançando $42,6 \%$ do resultado.

Os estudos revelaram também por análise de uma pesquisa da FUNDACE, que os advogados deram nota baixa no fator confiança em relação à Justiça brasileira, o que traz a interpretação da morosidade aumentar. Agregam-se ao fator morosidade, a demora no julgamento de ações judiciais e os processos que ficam represados sem soluções.

Os processos litigiosos obtiveram a pior pontuação, de acordo com pesquisa FUNDACE, o que reforça a percepção de lentidão no poder judiciário que são os verdadeiros vilões da morosidade.

Por fim, ao analisar o cruzamento das apreciações teóricas por meio da literatura e das respostas práticas pelos advogados respondentes, chegou-se à mesma conclusão dos fatores citados, em que todos contribuem em desfavor da celeridade processual

\section{Conclusão}


O objetivo geral desta pesquisa foi identificar as possíveis causas que emperram o andamento processual e que causam transtornos aos advogados no ordenamento jurídico brasileiro. Pode-se afirmar que o objetivo geral foi alcançado quando foi demonstrado por meio das teorias e das respostas práticas vividas pelos advogados, em que pode-se afirmar que a morosidade processual é um problema recorrente no Poder Judiciário relatado por diversos autores e pelos advogados questionados, e sendo este (a morosidade processual ) o principal obstáculo à garantia de direitos fundamentais e constitucionais do cidadão.

Como resultado da pesquisa, chegou-se à conclusão que por exaustivas análises e interpretações nos trabalhos estudados de diversos autores e pelas respostas dos advogados, que a questão morosidade processual ainda está longe de ser resolvida.

Por meio desta modesta pesquisa, a autora procurou contribuir com os estudos em torno do Poder Judiciário contribuindo com as seguintes propostas: avançar em possíveis mutirões de Juízes e serventuários, realizar alterações em processos de trabalho, contribuir para uma melhora no sistema de informatização e proporcionar uma melhor gestão da força de trabalho podem ser inúmeros indicadores de possíveis soluções para a eficácia e eficiência da celeridade dos processos no Poder Judiciário.

Contribui ainda a autora, afirmando que essas ações são necessárias e devem ser imediatas para oferecer uma maior celeridade processual, pois está nítido, que os advogados são os que mais sofrem diretamente com o lapso temporal processual, causando-Ihes com certeza constrangimentos para si e para com seus clientes.

Conclui-se que os princípios constitucionais trazidos à baila na EC de 2004 agasalhados na CF de 1988, são muito bem expressados no Sistema Judiciário, porém, esses princípios isolados, não garantem uma eficácia no contexto morosidade e um aumento de celeridade processual, pois pode perceber que há um sentimento de forma linear expressados pelos autores nas literaturas pesquisadas e pelos advogados questionados.

Nessa linha, pode-se inferir ainda que deve haver maior intervenção do CNJ no tocante aos processos parados nos tribunais do Brasil que somariam forças aos 
princípios constitucionais e os mesmos devem ser totalmente respeitados, pois é direito e garantia fundamental a razoável duração do processo.

Esse estudo não teve a intenção de findar ou esgotar sobre o assunto Morosidade Processual, portanto, sugere-se que novos estudos sejam realizados para encontrar novos resultados para confirmar o que este revelou ou apresentar novas propostas para colaborar com o Poder Judiciário brasileiro.

A autora agradece à Revista Multidisciplinar do Nordeste Mineiro pelo apoio ao desenvolvimento desta pesquisa e a seu pai que foi seu Orientador nesse estudo e pelos trabalhos já publicados do orientador nessa honrosa Revista, como citam-se:

i) Dificuldades da Inclusão de Pessoas com Deficiência no Mercado de Trabalho;

ii) Liderança: seu papel visando o clima e a cultura nas organizações;

iii) Desmotivação no ambiente de trabalho: fatores que geram medidas para a reversão;

iv) Inclusão de pessoas com deficiência no mercado de trabalho: a relevância das atividades mercadológicas e sociais;

v) O planejamento estratégico e o seu papel para a sobrevivência das micro e pequenas empresas;

vi) A cultura organizacional e sua relação com o desempenho das empresas e;

vii) Um estudo sobre o controle do estoque hospitalar com ênfase no gerenciamento sobre os custos e a armazenagem.

\section{Referências}

ABRÃO, Carlos Henrique. Processo Eletrônico. Revista Eletrônica. Janeiro / fevereiro de 2013. Disponível em <

https://juslaboris.tst.jus.br/bitstream/handle/20.500.12178/97236/2013_abrao_carlos _processo_eletronico.pdf?sequence=1> Acesso em 01 nov 2019.

\section{ADORNO, Sérgio; PASINATO, Wânia. A justiça no tempo, o tempo da justiça.}

Tempo Social, revista de sociologia da USP, v. 19, n. 2. 2007. 
AGÊNCIA SENADO. Senado notícias. Senado Federal. Brasília-DF, 2016

BONAVIDES, Paulo. Curso de Direito Constitucional. 27. ed. São Paulo: Malheiros, 2012.

BRASIL. Constituição da República Federativa do Brasil: 5 de outubro de 1988.

CHIUVITE JÚNIOR, Mario. Processo e justiça: uma reflexão à luz dos ideais éticos fundamentais no âmbito da pacificação dos conflitos judiciais (Tese de Doutorado). Universidade de São Paulo, São Paulo, 2010.

CONSELHO NACIONAL DE JUSTIÇA. Morosidade da Justiça é a principal reclamação recebida pela Ouvidoria do CNJ (2014). Disponível em:

<https://www.cnj.jus.br/morosidade-da-justica-e-a-principal-reclamacao-recebidapela-ouvidoria-do-cnj/>. Acesso em: 17 out. 2019.

CONSELHO NACIONAL DE JUSTIÇA. Congestionamento do Judiciário cai para 72\% em 2017 (2018). Disponível em: https://www.cnj.jus.br/congestionamento-dojudiciario-cai-para-72-em-2017/ Acesso em: 17 out. 2019.

COSTA, Anderson Yagi. Análise sobre a morosidade do poder judiciário brasileiro e propostas de intervenção. Universidade Federal de Goiás. Faculdade de Ciência e Tecnologia - FCT. Programa de Pós-Graduação em Administração Pública [Dissertação de Mestrado em Administração Pública] - PROFIAP. Goiânia GO, 2018.

DEMO, P. Metodologia do conhecimento científico. São Paulo: Atlas, 2000.

DENZIN, Norman K.; LINCOLN, Yvonna S. O Planejamento da Pesquisa Qualitativa. Porto Alegre: Artmed, 2006.

DOVERA, Ruth Lusia Duarte. Princípios constitucionais. Revista Eletrônica Direito e Política, Programa de Pós-Graduação Stricto Sensu em Ciência Jurídica da UNIVALI, Itajaí, v.7, n.2, 2º quadrimestre de 2012. Disponível em:

www.univali.br/direitoepolitica - ISSN 1980-7791. 
FOLLE, Ana Júlia Cecconello; SCHELEDER, Adriana Fasolo Pilati. As novas tecnologias e a uniformização do processo eletrônico: vantagem e desvantagens. 2014.

<http://publicadireito.com.br/artigos/?cod=e3998932e2e851de>. Acesso 01 nov 2019.

FUX, Luiz. Uma nova visão do universo jurídico. Revista da EMERJ, v.4, n.15, 2001.

MALHOTRA, N. Pesquisa de marketing: uma orientação aplicada. 3. ed. Porto Alegre: Bookman, 2006.

MENDES, Renato Souza. A morosidade processual frente os direitos fundamentais e a ineficiência da Administração Pública. Revista Jus Navigandi, ISSN 1518-4862, Teresina, ano 17, n. 3394, 16 out. 2012.

OLIVEIRA, Vallisney de Souza. CPC 2015 não enfrenta devidamente a morosidade processual. O juiz e o Novo Código de Processo Civil, Revista Consultor Jurídico, 2016.

REALE, Miguel. Filosofia do Direito. 11. ed. São Paulo: Saraiva, 1986.

Lições Preliminares de Direito. 19ª ed., São Paulo: Saraiva.1991.

Crise da justiça e arbitragem, 2004. Disponível em <http://www.miguelreale.com.br/artigos/justarb.htm>. Acesso em 18 ago. 2019.

RIBEIRO, Antônio de Pádua. O Judiciário como poder político no século XXI. Estudos avançados 14 (38), 2000.

ROCHA, Daniel de Almeida. Princípio da eficiência e processo: eficiência administrativa e eficiência processual em prol da razoável duração do procedimento 
judicial. [Dissertação de Mestrado]. Pontifícia Universidade Católica de Minas Gerais/Belo Horizonte, 2011.

SPALDING, Alessandra Mendes. Direito fundamental à tutela jurisdicional tempestiva à luz do inciso LXXVIII do art. 5 da CF inserido pela EC no 45/2004 . In: WAMBIER, Tereza Arruda Alvim. et. all (Coord.). Reforma do Judiciário: primeiras reflexões sobre a emenda constitucional n. 45/2004. São Paulo: Revista dos Tribunais, 2005. p. 501-514.

TUCCI, José Rogério Cruz. Tempo e Processo: uma análise empírica das repercussões do tempo na fenomenologia processual (civil e penal). São Paulo: Editora Revista dos Tribunais, 1997. 168 p.

VARGAS, Joana D. Estupro: que justiça? Tese de doutorado. Rio de Janeiro: lupe. RJ, 2004. 